\title{
Self-reported sitting time and physical activity: interactive associations with mental well-being and productivity in office employees
}

Anna Puig-Ribera 1,9*, Iván Martínez-Lemos², Maria Giné-Garriga ${ }^{3}$, Ángel Manuel González-Suárez , Judit Bort-Roig ${ }^{1}$, Jesús Fortuño ${ }^{5}$, Laura Muñoz-Ortiz ${ }^{6}$, Jim McKenna ${ }^{7}$ and Nicholas D Gilson ${ }^{8}$

\begin{abstract}
Background: Little is known about how sitting time, alone or in combination with markers of physical activity (PA), influences mental well-being and work productivity. Given the need to develop workplace PA interventions that target employees' health related efficiency outcomes; this study examined the associations between self-reported sitting time, PA, mental well-being and work productivity in office employees.

Methods: Descriptive cross-sectional study. Spanish university office employees $(n=557)$ completed a survey measuring socio-demographics, total and domain specific (work and travel) self-reported sitting time, PA (International Physical Activity Questionnaire short version), mental well-being (Warwick-Edinburg Mental Well-Being Scale) and work productivity (Work Limitations Questionnaire). Multivariate linear regression analyses determined associations between the main variables adjusted for gender, age, body mass index and occupation. PA levels (low, moderate and high) were introduced into the model to examine interactive associations.

Results: Higher volumes of PA were related to higher mental well-being, work productivity and spending less time sitting at work, throughout the working day and travelling during the week, including the weekends $(p<0.05)$. Greater levels of sitting during weekends was associated with lower mental well-being $(p<0.05)$. Similarly, more sitting while travelling at weekends was linked to lower work productivity $(p<0.05)$. In highly active employees, higher sitting times on work days and occupational sitting were associated with decreased mental well-being $(p<0.05)$. Higher sitting times while travelling on weekend days was also linked to lower work productivity in the highly active $(p<0.05)$. No significant associations were observed in low active employees.

Conclusions: Employees' PA levels exerts different influences on the associations between sitting time, mental well-being and work productivity. The specific associations and the broad sweep of evidence in the current study suggest that workplace PA strategies to improve the mental well-being and productivity of all employees should focus on reducing sitting time alongside efforts to increase PA.
\end{abstract}

Keywords: Sitting time, Physical activity, Mental well-being, Work productivity, Office employees

\footnotetext{
* Correspondence: annam.puig@uvic.cat

'Departament de Ciències de l'Activitat Física, Universitat de Vic, Barcelona, Spain

${ }^{9}$ Departament de Ciències de l'Activitat Física, Universitat de Vic, Carrer de la Sagrada Família, 7, 08500 Vic (Barcelona), Catalonia, Spain

Full list of author information is available at the end of the article
} 


\section{Background}

Combining sitting reduction strategies with efforts to increase physical activity (PA) are important and complementary public health priorities [1-8]. In a recent meta-analysis, each additional hour of daily sitting - in adults who sat for $>7$ hours/day - increased risk in allcause mortality by $2 \%$ [4]. The risk of dying from all causes increased to $5 \%$ for those who were also inactive, suggesting that PA may offer some protection against the harm of prolonged sitting time.

While the chronic disease benefits of sitting less and being more active are increasingly well documented [1-8], and associations observed between PA and mental wellbeing and work performance/productivity improvements [9-13], little is known about how sitting time influences these important workplace indices. Instead, existing research has explored associations between sitting time and markers of mental health, such as depressive symptoms, rather than well-being [14]. Further, what is known has only addressed non-occupational sitting time [15]. Recently, a small study of Australian office employees $(n=108)$ identified that more time spent sitting before and after work was associated with lost work productivity (odds ratio $=2.58$; 95\% CI: 1.08 to 6.20) [16]. This study used an objective indicator of sitting time (accelerometers) to explore relationships with 'on the job' productivity indicators; interactions between behaviors were not assessed.

Given a limited evidence base, research is required to investigate the potential interactions between sitting time and PA, relative to mental well-being and work productivity. Such formative research will be valuable for developing interventions targeting specific employee behaviors that improve both health and efficiency-related outcomes. Consequently, this study examined relationships between self-reported sitting time, PA, mental well-being and work productivity in a sample of Spanish office employees.

\section{Methods}

Participants

Following ethics clearance, around 2,500 emails were sent to academic and administrative employees at each of four Spanish universities in Galicia, the Basque Country and Catalonia $(\times 2)$. Emails invited employees to participate in a workplace PA program to increase step counts and reduce occupational sitting time. Respondents to this initial email $(n=704)$ were asked to complete an on-line survey (April- December 2010) prior to intervention. Informed consent was provided during survey completion. The study was approved by the following ethics committee of each university: Ethics Committee of the Faculty in Psychology, Education and Sport Sciences (University Ramon Llull); Research Commission of University of Vic; Ethics Committee of Clinical Research in Conselleria de Sanidad (CEIC; Xunta de Galicia); Ethics Committee of Applied
Research in Human Beings (CEISH/GIEB; University of the Basque Country).

\section{Measures}

A 22-item survey assessed socio-demographic variables (age, gender, weight, height and occupation [academic or administrator], PA levels [17], sitting time [18], mental well-being [19] and work productivity loss [20]. For PA, the International Physical Activity Questionnaire (IPAQ) short form assessed walking, moderate and vigorous intensity PA [17]. The IPAQ short form shows good reliability (Spearman's $\rho=0.80$ ) and moderate criterion validity with accelerometers (Spearman's $\rho=0.30$ ) in the general [17] as well as Catalan and Spanish populations [21].

Time spent in these activities was combined to show the volume of activity relative to energy expenditure (Metabolic Equivalent Units - METs), yielding a score in weekly MET-minutes. Employees were classified into either low ( $\geq 599$ MET-minutes/week), moderate (at least 600-2,999 MET-minutes/week) or high (3,000+ METminutes/week) PA categories.

A seven-day total and domain-specific sitting questionnaire assessed weekly sitting time (minutes/day) at work and while travelling [18]. These domains were targeted within a workplace PA intervention that aimed to reduce sitting time (i) at work and (ii) while commuting. This questionnaire has high validity and reliability in the adult population for weekday sitting time at work ( $\mathrm{r}=$ 0.69-0.74), while it is lower for weekend days across all domains $(r=0.23-0.74)$ [18]. Forward-backward translation into Catalan and Spanish identified linguistic equivalence [22].

The Warwick-Edinburg Mental Wellbeing Scale (WEMWBS) assessed positive mental well-being (positive functioning, happiness and subjective wellbeing) over the previous two weeks [19]. The 14-item scale has five response categories; 1 ("None") to 5 ("All the time"). Responses are summed to identify the final score, 14-70, indicating low to high positive mental well-being. WEMWBS shows high internal reliability (Cronbach's alpha $=0.93)$ and one week test-retest reliability $(r=0.97)$ in the Spanish population [23].

The Work Limitations Questionnaire (WLQ) was used to assess performance and the degree to which health problems interfered with the ability to perform job roles [20]. Spanish [24] and Catalan [25] versions of the WLQ have been developed and validated. In the WLQ, respondents self-report levels of difficulty in performing 25 specific job roles across four scales, with scores expressed as an average of responses. The 5-item "Time Scale" addresses difficulty in scheduling demands. For the "MentalInterpersonal Scale" six items cover difficulty performing cognitive tasks involving the processing of sensory information and interacting with others on-the-job. The 
Table 1 Baseline data on the main outcomes and socio-demographic variables

\begin{tabular}{|c|c|}
\hline & $N=557$ \\
\hline \multicolumn{2}{|l|}{ Gender, $\mathrm{n}(\%)$} \\
\hline Male & $215(38.7)$ \\
\hline Female & $314(61.3)$ \\
\hline Age, mean (SD) & $42(9)$ \\
\hline Body Mass Index $\left(\mathrm{kg} / \mathrm{m}^{2}\right)$, mean (SD) & $24.86(10.82)$ \\
\hline \multicolumn{2}{|l|}{ University, n (\%) } \\
\hline Vic (Catalonia) & $110(19.8)$ \\
\hline Basque Country & $112(20.1)$ \\
\hline Ramon Llull - Blanquerna (Catalonia) & $73(13.1)$ \\
\hline Vigo & $261(46.9)$ \\
\hline \multicolumn{2}{|l|}{ Occupation, n (\%) } \\
\hline Academic Staff & $340(63.4)$ \\
\hline Administrative Staff & $196(36.6)$ \\
\hline $\begin{array}{l}\text { Physical Activity (MET-minutes/week), } \\
\text { median (interquartile range) }\end{array}$ & $2,742(1,238-4,921)$ \\
\hline \multicolumn{2}{|l|}{ Physical Activity ${ }^{1}$ (MET-minutes/week), n (\%) } \\
\hline Low & $169(31.5)$ \\
\hline Moderate & $151(28.1)$ \\
\hline High & $217(40.4)$ \\
\hline $\begin{array}{l}\text { Mental Well-Being at work (WEMWBS) }{ }^{2} \text {, } \\
\text { mean (SD) }\end{array}$ & $52.6(7.1)$ \\
\hline \multicolumn{2}{|l|}{$\begin{array}{l}\text { Presenteeism (WLQ) }{ }^{3} \text {, median } \\
\text { (interquartile range) }\end{array}$} \\
\hline Time scale ${ }^{4}$ & $15(5-25)$ \\
\hline Mental-Interpersonal scale $e^{5}$ & $17(8-28)$ \\
\hline Output scale ${ }^{6}$ & $21(8-29)$ \\
\hline $\begin{array}{l}\% \text { of work productivity loss (WLQ } \\
\text { Index Score) }{ }^{7} \text {, median (interquartile range) }\end{array}$ & $4.5(2.5-6.6)$ \\
\hline \multicolumn{2}{|l|}{ SITTING } \\
\hline $\begin{array}{l}\text { Time spent sitting at work (min/day), } \\
\text { mean (SD) }\end{array}$ & $287(147)$ \\
\hline \multicolumn{2}{|l|}{$\begin{array}{l}\text { Time spent sitting traveling to and } \\
\text { from places (min/day), mean (SD) }\end{array}$} \\
\hline Weekdays & $72(48)$ \\
\hline Weekend days & $50(48)$ \\
\hline
\end{tabular}

Total time spent sitting (min/day), mean (SD)
Table 1 Baseline data on the main outcomes and socio-demographic variables (Continued)

Weekdays
Weekend days
SD: Standard Deviation.
${ }^{1}$ High category: achieving a minimum total physical activity of at least
3,000 MET-minutes/weeks.
Moderate category: achieving a minimum total physical activity of at least
600 MET-minutes/weeks.
Low category: Individuals who do not meet criteria for categories 2 or 3 .
${ }^{2}$ Warwick-Edinburgh Mental Well-being Scale (WEMWBS): The minimum score
is 14 and the maximum is 70 . Higher scores indicate better positive
mental well-being.
${ }^{3}$ Each scale score indicates the percentage of time in the previous two weeks
when the respondent was limited in performing a specific dimension of job
tasks (from low to high rate of difficulty in performing job demands). The
minimum score is 0 (limited none of the time) to 100 (limited all of the time).
${ }^{4}$ Five items addressing difficulty in scheduling demands.
${ }_{5}^{5}$ Six items covering difficulty performing cognitive tasks at work.
${ }^{6}$ Five items addressing decrements in the ability to meet demands for
quantity, quality and timeless of completed work.
${ }^{7} \mathrm{~A}$ percentage estimate of work loss based on the weighted sum of the scores
from the WLQ scales.

"Output Scale" has five items exploring limitations in meeting demands for quantity, quality and timeliness of completed work. The nine-item "Physical Scale" assesses ability to perform job tasks that involve bodily strength, movement, endurance, coordination and flexibility.

Sub-scales scores are transformed to a 0-100 continuum to represent the amount of time in the previous two weeks affected by limited on-the-job performance (from low to high rate of difficulty). These scales estimate work loss, known as the WLQ index [20], which is the weighted sum of the scores from the WLQ scales. In the present study, the WLQ index was calculated by summing the scores of three WLQ scales; the "Physical Scale" was excluded from the current analyses as it was not relevant to these job roles.

\section{Analyses}

Data on key outcome variables were described using frequencies (percentage), means (standard deviation) and medians (interquartile range). Bivariate linear regression analyses assessed associations between self-reported sitting time (total and domain specific), PA, mental wellbeing and work productivity. The model was adjusted for demographics and stratified by PA level introducing an interaction term between PA level (low, moderate or highly active) [17] and sitting time into a multivariate regression model. Significance was set at $\mathrm{p}<0.05$ and analyses performed using Strata software, version 12.

\section{Results}

Five-hundred and fifty-seven university office employees completed the survey, giving a response rate of 79\% (557/ 704) from the initial respondents. Table 1 shows descriptive baseline data on the main variables as well as gender, mean age, mean body mass index, universities and staff 
occupation. Compared to males, females averaged 2.09 points lower on the WEMWBS scale indicating lower mental well-being $(\mathrm{p}<0.05$; Table 2$)$.

A higher body mass index was also significantly associated with greater losses in work performance $(\mathrm{p}<0.05$; Table 2) and an increased difficulty in achieving scheduling demands, performing cognitive tasks and interacting with others on the job $(\mathrm{p}<0.05$; Table 2$)$. No significant associations were identified between body mass index, mental well-being or meeting demands for quantity and quality of completed work.

Higher volumes of PA (MET-minutes/week) were positively related to better mental well-being $(\mathrm{p}<0.05$; Table 2$)$.
While the least active employees reported the lowest WEMWBS scores, employees who did more PA reported higher scores (Figure 1). As PA rose from zero METsminute/week, average WEMWBS scores rose sharply. However, WEMWBS averages were similar with higher levels of PA (Figure 1). Higher PA (MET-minutes/week) was also beneficially associated with the percentage of lost work performance $(\mathrm{p}<0.05$; Table 2$)$. The least active employees reported the greatest percentages of lost productivity compared to the most active employees (Figure 2). As PA rose from zero METs-minute/week, the percentage of lost work performance was sharply reduced; the lowest level of lost work performance was

Table 2 Associations between mental well-being, work productivity loss and the scales for presenteeism with sitting time, PA and socio-demographic characteristics

\begin{tabular}{|c|c|c|c|c|c|}
\hline & $\begin{array}{l}\text { Mental Well-Being } \\
\text { at work (WEMWBS) }\end{array}$ & $\begin{array}{l}\text { WLQ Index Score }{ }^{2} \% \\
\text { of lost work } \\
\text { productivity }\end{array}$ & $\begin{array}{l}\text { Presenteeism } \\
(\text { WLQ) } \\
\text { scale }^{3} \text { Time }\end{array}$ & $\begin{array}{l}\text { Presenteeism (WLQ) } \\
\text { Mental-Interpersonal } \\
\text { scale }^{5}\end{array}$ & $\begin{array}{l}\text { Presenteeism (WLQ) } \\
\text { Output scale }^{6}\end{array}$ \\
\hline \multicolumn{6}{|l|}{ Gender } \\
\hline Male & 1 & 1 & 1 & 1 & 1 \\
\hline Female & $-2.09(-3.33,-0.85)^{*}$ & $0.22(-0.60,1.05)$ & $2.45(-1.29,6.20)$ & $2.37(-1.44,6.18)$ & $-0.22(-4.30,3.87)$ \\
\hline Age & $0.05(-0.02,0.11)$ & $0.002(-0.041,0.045)$ & $-0.10(-0.30,0.09)$ & $-0.09(-0.29,0.10)$ & $0.08(-0.13,0.30)$ \\
\hline Body Mass Index $\left(\mathrm{kg} / \mathrm{m}^{2}\right)$ & $-0.02(-0.07,0.04)$ & $0.033(0.004,0.063)^{*}$ & $0.15(0.01,0.29)^{*}$ & $0.16(0.02,0.31)^{*}$ & $0.13(-0.03,0.28)$ \\
\hline \multicolumn{6}{|l|}{ Occupation } \\
\hline Academic Staff & 1 & 1 & 1 & 1 & 1 \\
\hline Administrative Staff & $-0.22(-1.46,1.03)$ & $-0.39(-1.18,0.39)$ & $-0.29(-3.86,3.27)$ & $-1.70(-5.46,2.05)$ & $-4.39(-8.45,-0.33)^{*}$ \\
\hline $\begin{array}{l}\text { Physical Activity } \\
\text { (MET-minutes/week) }\end{array}$ & $0.66(0,09,1,22)^{*}$ & $-0.50(-0.91,-0.09)^{*}$ & $-1.47(-3.32,0.38)$ & $-1.14(-3.00,0.72)$ & $-3.25(-5.25,-1.25)^{*}$ \\
\hline \multicolumn{6}{|l|}{$\begin{array}{l}\text { Physical Activity } \\
\text { (MET-minutes/week) }\end{array}$} \\
\hline Physical activity low level & 1 & 1 & 1 & 1 & 1 \\
\hline $\begin{array}{l}\text { Physical activity moderate } \\
\text { level }\end{array}$ & $0.53(-1.26,2.31)$ & $-1.21(-2.16,-0.26)^{*}$ & $-7.31(-11.64,-2.99)^{*}$ & $-4.84(-9.28,-0.41)^{*}$ & $-4.69(-9.50,0.11)$ \\
\hline Physical activity high level & $2.33(0.63,4.02)^{*}$ & $-1.71(-2.68,-0.75)^{*}$ & $-7.88(-12.24,-3.52)^{*}$ & $-7.27(-11.76,-2.77)^{*}$ & $-7.70(-12.52,-2.88)^{*}$ \\
\hline \multicolumn{6}{|l|}{ SITTING $^{8}$} \\
\hline $\begin{array}{l}\text { Time spent sitting at work } \\
\text { (min/day) }\end{array}$ & $-0.004(-0.072,0.064)$ & $0.05(-0.009,0.1)$ & $0.17(-0.08,0.42)$ & $0.25(-0.02,0.52)$ & $0.30(-0.01,0.59)^{*}$ \\
\hline \multicolumn{6}{|l|}{$\begin{array}{l}\text { Time spent sitting travelling } \\
\text { (min/day) }\end{array}$} \\
\hline Weekdays & $0.02(-0.17,0.20)$ & $-0.002(-0.13,0.12)$ & $0.15(-0.41,0.72)$ & $-0.03(-0.61,0.55)$ & $-0.11(-0.73,0.50)$ \\
\hline Weekend days & $-0.18(-0.37,0,01)^{*}$ & $0.14(0,01,0.27)^{*}$ & $0.70(0.12,1.29)^{*}$ & $0.75(0.16,1.34)^{*}$ & $0.62(-0.01,1.26)^{*}$ \\
\hline \multicolumn{6}{|l|}{ Total sitting time (min/day) } \\
\hline Weekdays & $0.02(-0.03,0.06)$ & $0.02(-0.02,0.07)$ & $0.11(-0.08,0.31)$ & $0.13(-0.06,0.33)$ & $0.11(-0.10,0.32)$ \\
\hline Weekend days & $-0.10(-0.14,-0.05)^{*}$ & $0.01(-0.03,0.05)$ & $0.09(-0.11,0.28)$ & $0.14(-0.06,0.33)$ & $0.16(-0.05,0.37)$ \\
\hline \multicolumn{6}{|c|}{$\begin{array}{l}{ }^{*} \mathrm{p}<0.05 . \\
{ }^{1} \text { Warwick-Edinburgh Mental Well-being Scale (WEMWBS): Scores range } 14 \text { to } 70 \text {. Higher scores indicate better positive mental well-being. } \\
{ }^{2} \mathrm{~A} \text { percentage estimate of work loss based on the weighted sum of the scores from the Work Limitations Questionnaire (WLQ) scales. } \\
{ }^{3} \text { The estimated percentage of time in the previous two weeks spent feeling limited in performing a specific dimension of job tasks (rated from low } \\
\text { to high difficulty). }\end{array}$} \\
\hline
\end{tabular}




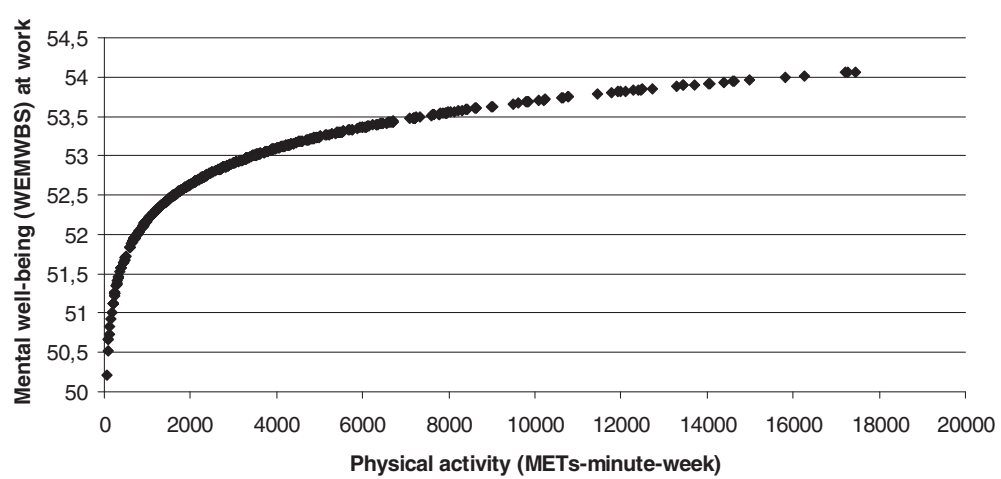

Figure 1 Significant positive non-linear association between physical activity (METs-minute-week) and mental well-being (WEMWBS) at work. 'Warwick-Edinburgh Mental Well-being Scale (WEMWBS): The minimum score is 14 and the maximum is 70 . Higher scores mean better positive mental well-being.

reported among employees doing most PA (Figure 2). A consistent pattern showed that progressively more PA was inversely linked to the time employees spent feeling limited in their capacities (Table 2). This was shown for (i) scheduling demands (linked to a $22.60 \%, 15.86 \%$ and $14.67 \%$ of time feeling limited for the low, moderate and high PA categories respectively), (ii) performing mentalinterpersonal tasks $(24.42 \%, 20.16 \%$ and $17.12 \%)$ and (iii) delivering outputs $(28.16 \%, 23.73 \%$ and $21.24 \%)$ (Table 2). Each category of PA was linked to a smaller, but still progressive, percentage estimate for lost work productivity; $5.99 \%, 4.95 \%$ and, $4.36 \%$ (Table 2 ).

Higher volumes of PA were also associated with spending less time sitting at work and throughout the working day ( $\mathrm{p}<0.05$; Figures 3 and 4 ). While the least active employees reported higher times of occupational sitting and daily sitting during weekdays, employees engaged in high volumes of PA reported the least time sitting on both domains (Figures 3 and 4). As PA MET minutes/week rose from zero, the average minutes spent sitting at work and during working days reduced. However, the rate of decrease on occupational and total weekday sitting time lessened when PA was high (Figures 3 and 4). Contrarily, higher volumes of PA were significantly associated with spending more time sitting at weekends $(\mathrm{p}<0.05$; Figure 5). As PA increased from zero METs-minute/ week, the average of minutes spent sitting at weekends increased more sharply than when PA was higher (Figure 5). Higher volumes of PA were also significantly associated with less time spent sitting while travelling during weekends and weekdays $(\mathrm{p}<0.05)$. While low active employees spent an average of 62 minutes/day sitting during weekend travel, the comparable average for moderately and highly active employees was 45 (62.38 to 17.61) minutes/ day. Similarly, for weekday travelling low active employees averaged 77 minutes/day sitting compared to 59 (77.03 to 18.38) minutes/day for the moderately active $(\mathrm{p}<0.05)$.

Two domains of sitting time showed significant negative linear associations with positive mental well-being $(\mathrm{p}<0.05$; Table 2). Greater levels of sitting in weekend travelling and total weekend sitting time were associated with lower mental well-being; sitting 30 extra minutes a day in each domain was linked to a reduction of $0.6 \%$ and $0.4 \%$ respectively; 0.36 and 0.20 points in the

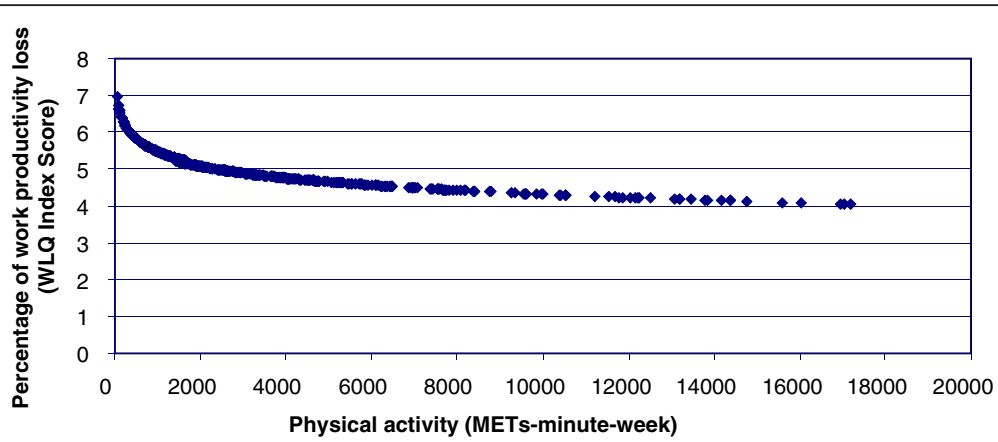

Figure 2 Significant negative non-linear association between physical activity (METs-minute-week) and percentage of work productivity loss (WLQ Index Score). ${ }^{1}$ Estimate of the percentage of work loss based on the weighted sum of the scores from the Work Limitations Questionnaire scales. 


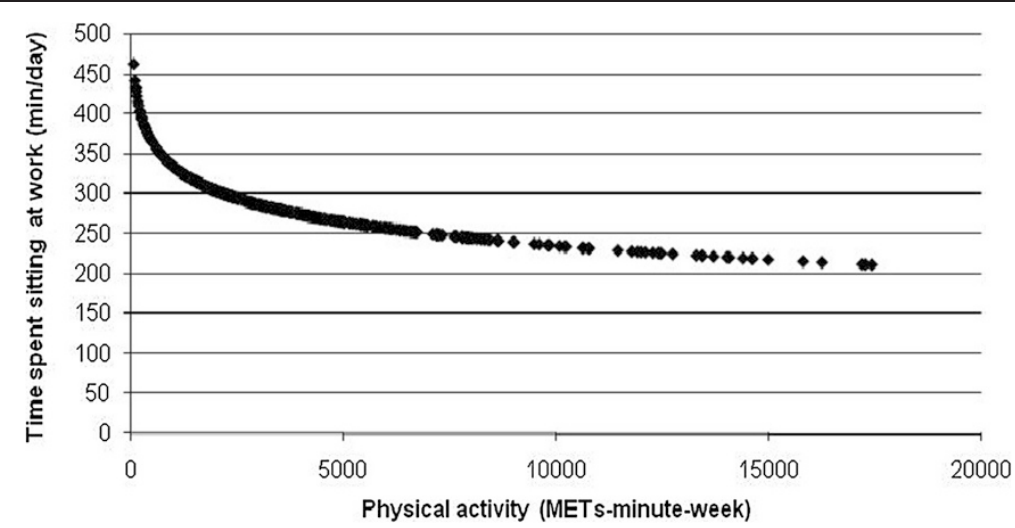

Figure 3 Significant negative non-linear association between physical activity (METs-minute-week) and occupational sitting time.

WEMWBS score respectively $(\mathrm{p}<0.05$; Table 2$)$. No significant associations were found between weekday occupational and total sitting time for mental well-being.

Time spent sitting during weekend travelling also showed an inverse relationship with work productivity ( $\mathrm{p}<0.05$; Table 2). More sitting during weekend travelling was related to greater difficulties in meeting job demands (every extra 30 minutes/day was linked with an additional $1.4 \%$ difficulty in meeting job scheduling demands, a $1.5 \%$ increase in difficulty performing cognitive tasks or tasks that involved interacting with others and a $1.2 \%$ increase in the difficulty of meeting demands for quantity, quality and timeless of completed work). Greater levels of sitting while travelling at weekends were also linked to lower overall work productivity (each additional block of 30 minutes/day was linked to a reduction of $0.3 \%$ $(\mathrm{p}<0.05$; Table 2$)$. There were no significant associations between productivity and occupational or total sitting time.

In highly active employees, greater levels of sitting at work, throughout the work day and while travelling during weekend was related to lower mental well-being (for each increment of 30 minute/day was related to a reduction of $0.6 \%, 0.36 \%$ and $1.9 \%$ respectively $(0.34,0.2$ and 1.06 points in the WEMWBS scores; Table 3). This association was not significant for inactive employees (Table 3). Greater levels of sitting in weekend travel was also linked to lower work productivity in the highly active (each additional 30 minutes was associated with a $0.8 \%$ reduction). Among inactive employees, no domain of work productivity was linked to higher sitting time.

\section{Discussion}

This study examined the associations between sitting time and PA, with mental well-being and work productivity in 557 office employees. Uniquely, the study addresses crosssectional differences in how indices of sitting, alone or in combination with markers of PA, relate to mental wellbeing and productivity. Given the need to develop workplace PA interventions that target employees' health related efficiency outcomes, this study provides novel insights of the interactive relationships between sitting time and PA. This evidence contributes to a better understanding of how targeting both behaviors can

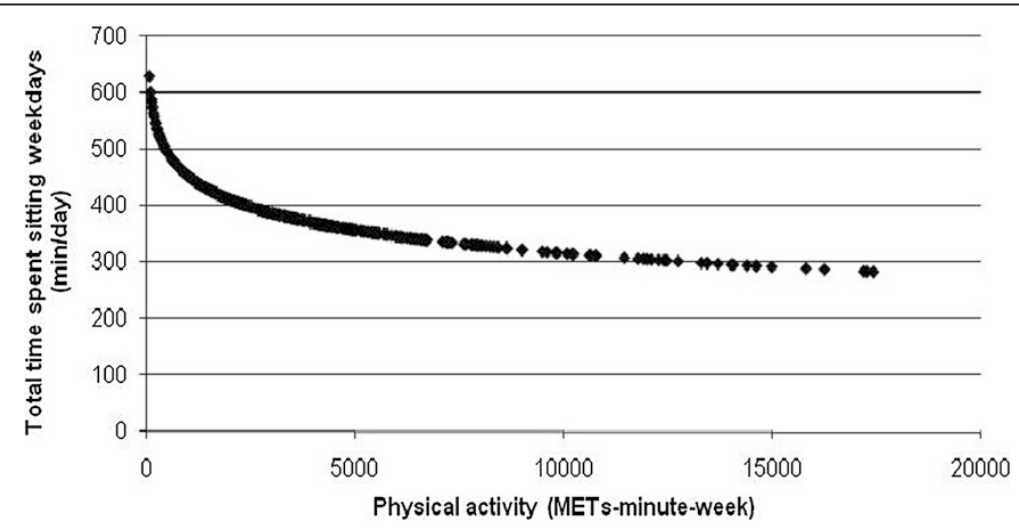

Figure 4 Significant negative non-linear association between physical activity (METs-minute-week) and total time spent sitting during weekdays. 


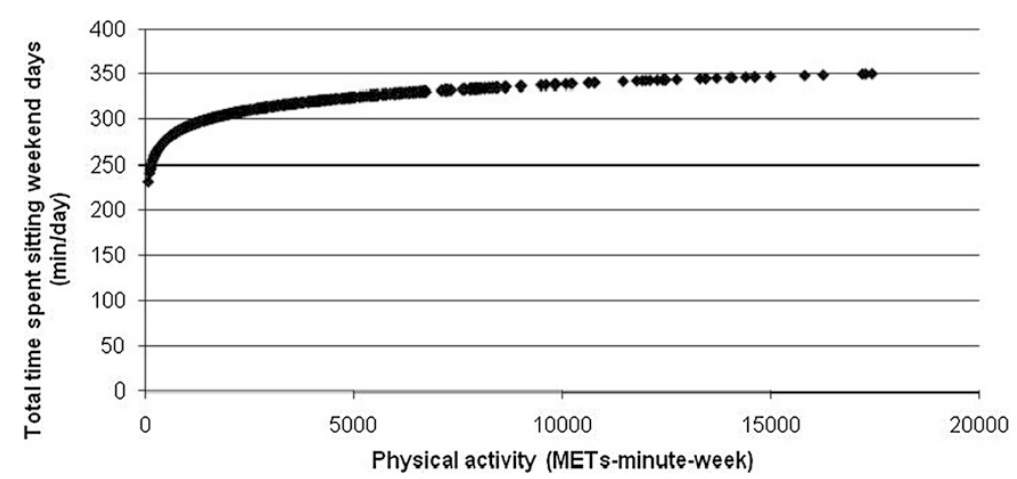

Figure 5 Significant positive non-linear association between physical activity (METs-minute-week) and total time spent sitting on weekend days.

potentially benefit the mental well-being and productivity of office employees.

The main finding of the present study indicated that employees' PA levels exerted different influences on the associations between sitting time, mental well-being and work productivity. Previous research has reported adverse associations between prolonged sitting time and well-being in adults $[15,26]$. However, these studies have focused on leisure-time sitting (i.e. television viewing and screen-based sitting) rather than on investigating how employees' PA levels might interact on the results of occupational sitting time and subsequent effects on mental well-being. While several studies have examined joint associations between PA and sitting time with physical health outcomes $[27,28]$, few have investigated the interactive effects of PA and sitting time relative to mental well-being.

Rosenkranz et al. [29] identified that PA was positively associated with excellent overall health (OR 2.22, 95\% $\mathrm{CI}=2.20 .2 .47)$ and quality of life (OR=1.13, 95\% $\mathrm{CI}=1.09,1,18)$, interactions between PA and sitting time were not statistically significant. Similarly, Södergren et al. [30] addressed the relationship between leisure PA and sitting time to examine their associations with good selfreported health. No associations between sitting time and self-rated health were identified using multivariate analysis. However, both of these studies [29,30] measured total daily sitting time by asking participants to report total hours per day usually spent sitting (using IPAQ short and long forms). Neither investigated the joint associations between PA and different domains of sitting time relative to mental well-being.

In our study, spending more time sitting at work and during workdays was linked to lower mental well-being in the highly active employees but not in their inactive counterparts. A possible explanation could be the relationship identified in our sample between PA and both sitting time domains. While highly active employees averaged 3.5 hours sitting at work and 5.4 hours/day sitting from Mondays to Fridays, their low active counterparts averaged 5.15 hours/day and 7.11 hours/day sitting respectively. For highly active employees, increasing sitting time may indicate a decline healthy daily behavior, with negative consequences for their mental wellbeing. Even though no threshold for sitting time has been linked to diminished mental well-being, previous research has identified that sitting for more than 7 hours/day was associated with an increased likelihood of depressive symptoms in women [31]. Since adopting one healthy lifestyle behavior can facilitate adopting another [32], and similarly for negative behavior, future research should examine how changes to the domains of sitting time relate to mental well-being in highly active employees.

For the same group, higher volumes of time spent sitting travelling at weekends were associated with both poorer work performance and poorer mental well-being. To our knowledge, no previous studies have investigated the joint associations between PA with total and specific domains of sitting time relative to employees' work performance. Our results indicated that time spent sitting while travelling during non-working days influenced employees' work productivity and, that PA levels exerted an influence on this association. Again, this may be explained by the relationship identified in our sample between PA and sitting time while travelling at weekends; with highly active employees sitting 17 minutes/day less while travelling on Saturday and Sundays than their inactive counterparts. While a recent systematic review [33] identified that the most commonly assessed subtypes of sitting domains were TV viewing, total sitting, general screen and occupational sitting time - with each being associated with lower levels of PA - few studies have examined how specific sitting domains during nonworking days are influenced by PA levels or vice versa. Even less is known about how this relates to workrelated issues such as work productivity or performance. Our results are partly consistent with previous research 
Table 3 Interaction between PA levels and sitting time relative to mental well-being, work productivity loss and the scales for presenteeism adjusted for demographics

\begin{tabular}{|c|c|c|c|c|c|}
\hline & $\begin{array}{l}\text { Mental Well-Being } \\
\text { at work (WEMWBS) }\end{array}$ & $\begin{array}{l}\text { WLQ Index Score }{ }^{2} \% \\
\text { of lost work } \\
\text { productivity }\end{array}$ & $\begin{array}{l}\text { Presenteeism } \\
(\text { WLQ) } \\
\text { scale }^{3} \text { Time }\end{array}$ & $\begin{array}{l}\text { Presenteeism (WLQ) } \\
\text { Mental-Interpersonal } \\
\text { scale }^{5}\end{array}$ & $\begin{array}{l}\text { Presenteeism } \\
\text { (WLQ) Output } \\
\text { scale }^{6}\end{array}$ \\
\hline \multicolumn{6}{|l|}{$\begin{array}{l}\text { Time spent sitting at work } \\
(\min / \text { day })^{7}\end{array}$} \\
\hline Physical activity low level & $-0.10(-0.32,0.13)$ & $0.004(-0.12,0.13)$ & $0.09(-0.46,0.63)$ & $-0.02(-0.61,0.56)$ & $0.19(-0.78,0.41)$ \\
\hline Physical activity moderate level & $-0.13(-0.27,0.01)$ & $0.03(-0.06,0.11)$ & $0.03(-0.39,0.32)$ & $0.20(-0.19,0.58)$ & $0.24(-0.19,0.67)$ \\
\hline Physical activity high level & $-0.17(-0.31,-0.03)^{*}$ & $0.07(-0.02,0.16)$ & $0.32(-0.06,0.69)$ & $0.32(-0.11,0.75)$ & $0.33(-0.13,0.79)$ \\
\hline \multicolumn{6}{|l|}{$\begin{array}{l}\text { Time spent sitting travelling to } \\
\text { and from places on weekdays } \\
\text { (min/day) }\end{array}$} \\
\hline Physical activity low level & $0.21(-0.16,0.59)$ & $-0.17(-0.41,0.06)$ & $-0.59(-1.77,0.59)$ & $-0.58(-1.64,0.48)$ & $-1.00(-2.24,0.24)$ \\
\hline Physical activity moderate level & $0.02(-0.35,0.40)$ & $-0.04(-0.27,0.18)$ & $-0.28(-1.17,0.60)$ & $0.01(-0.99,1.01)$ & $-0.07(-1.18,1.04)$ \\
\hline Physical activity high level & $-0.07(-0.36,0.21)$ & $0.08(-0.10,0.26)$ & $0.63(-0.16,1.42)$ & $0.06(-0.88,1.00)$ & $-0.11(-1.17,0.95)$ \\
\hline \multicolumn{6}{|l|}{$\begin{array}{l}\text { Time spent sitting travelling } \\
\text { to and from places on } \\
\text { weekend days (min/day) }\end{array}$} \\
\hline Physical activity low level & $0.22(-0.15,0.58)$ & $-0.15(-0.38,0.07)$ & $-0.73(-1.88,0.42)$ & $-0.44(-1.47,0.59)$ & $-0.80(-1.95,0.35)$ \\
\hline Physical activity moderate level & $-0.23(-0.62,0.15)$ & $-0.05(-0.28,0.19)$ & $-0.24(-1.21,0.73)$ & $0.22(-0.81,1.24)$ & $-0.12(-1.30,1.07)$ \\
\hline Physical activity high level & $-0.53(-0.84,-0.22)^{*}$ & $0.40(0.21,0.59)^{*}$ & $1.83(0.99,2.66)^{*}$ & $1.61(-0.59,2.63)^{*}$ & $1.47(0.40,2.54)^{*}$ \\
\hline \multicolumn{6}{|l|}{$\begin{array}{l}\text { Total time spent sitting on } \\
\text { weekdays (min/day) }\end{array}$} \\
\hline Physical activity low level & $-0.02(-0.14,0.10)$ & $-0.03(-0.11,0.05)$ & $-0.15(-0.57,0.27)$ & $-0.04(-0.38,0.31)$ & $-0.21(-0.59,0.17)$ \\
\hline Physical activity moderate level & $-0.14(-0.26,-0.02)^{*}$ & $0.02(-0.05,0.09)$ & $0.03(-0.27,0.33)$ & $0.16(-0.15,0.47)$ & $0.14(-0.23,0.50)$ \\
\hline Physical activity high level & $-0.10(-0.21,-0.002)^{*}$ & $0.06(-0.01,0.12)$ & $0.28(-0.01,0.58)$ & $0.19(-0.16,0.54)$ & $0.13(-0.23,0.50)$ \\
\hline \multicolumn{6}{|l|}{$\begin{array}{l}\text { Total time spent sitting on } \\
\text { weekend days }(\mathrm{min} / \text { day) }\end{array}$} \\
\hline Physical activity low level & $-0.10(-0.21,0.001)$ & $-0.01(-0.07,0,06)$ & $0.06(-0.29,0.41)$ & $0.12(-0.19,0.42)$ & $0.06(-0.26,0.39)$ \\
\hline Physical activity moderate level & $-0.03(-0.15,-0.09)$ & $-0.03(-0.04,0.10)$ & $0.16(-0.13,0.45)$ & $0.09(-0.23,0.41)$ & $0.25(-0.11,0.61)$ \\
\hline Physical activity high level & $-0.03(-0.15,0.10)$ & $-0.02(-0.10,0.06)$ & $-0.12(-0.48,0.24)$ & $0.03(-0.40,0.47)$ & $-0.15(-0.58,0.27)$ \\
\hline \multicolumn{6}{|c|}{$\begin{array}{l}\text { * } \mathrm{F}<0.05 \text {. } \\
{ }^{1} \text { Warwick-Edinburgh Mental Well-being Scale (WEMWBS): Scores range } 14 \text { to } 70 \text {. Higher scores mean better positive mental well-being. } \\
{ }^{2} \mathrm{~A} \text { percentage estimate of work loss based on the weighted sum of the scores from the Work Limitations Questionnaire (WLQ) scales. } \\
{ }^{3} \mathrm{~A} \text { percentage estimate of time in the previous two weeks spent feeling limited in performing a specific dimension of job tasks (rated from low to high difficulty). } \\
{ }^{4} \text { Five items addressing difficulty in scheduling demands. } \\
{ }^{5} \text { Six items cover difficulty performing cognitive tasks involving the processing of sensory information and a person's problems interacting with people on-the-job. } \\
{ }^{6} \text { Five items address decrements in the ability to meet demands for quantity, quality and timeless of completed work. } \\
{ }^{7} \text { The coefficients of the different domains of sitting correspond to an increase of } 15 \text { min/day. }\end{array}$} \\
\hline
\end{tabular}

that indicates that highly active employees sit less at work and also outside work [34], including commuting, even though the previous study only referenced commuting on weekdays. However, the associations found in our sample between PA and total sitting time during non-working days suggests a different pattern of sedentary and PA behaviors during non-working days. This change in patterns is consistent with a previous study indicating that the time periods of 06:00-07:00 and 17:00-19:00, which are typically outside normal working hours, represent the periods when moderate-tovigorous PA is significantly higher in work days than non-working days [35]; being at work from 09:00-17:00 clearly influences employees' sedentary and PA patterns during the workdays [35]. Furthermore, previous research has suggested that engaging in sitting behaviors is related to having more leisure time, which mainly happens on the weekends of working adults [36] and that sitting time during non-working days is explained by different correlates (i.e. home and neighborhood factors) than working days [36]. Future research should investigate the effects sedentary patterns on non-working days have on work productivity as well as mental well-being.

Finally, it should be pointed out that more sitting time domains were related to mental well-being than to work productivity. Nonetheless, mental well-being has been associated with work productivity and other work-related outcomes (i.e. job stress), indicating that specific domains 
of sitting time could also indirectly influence work productivity. A recent longitudinal study identified that employees in the low well-being segment reported over 3 times the level of work productivity loss than those in the high well-being segment [37]. Over a year, changes in well-being were significantly associated with positive changes in employees' productivity [37]. Additionally, levels of positive mental well-being reduce as work stress increases [38]; work stress is one of the most commonly reported causes of work-related illness and loss of work performance [38].

This study has several important limitations. As a crosssectional study, it is not possible to establish cause-effect relationships between sitting time, PA, mental well-being and productivity. Furthermore, the data can only indicate associations; studies are needed to address the directionality of these associations. More PA and less sitting may be result of better mental health and performance. However, descriptive analyses are essential for documenting the potential benefits of health promotion initiatives [39] for employees. This descriptive study provides a valuable baseline for developing workplace interventions aimed at improving employees' well-being and work productivity through sitting behavior and PA. It is also important to recognize that our findings are specific to office employees (highly educated middle-age men and women) who showed an interest to participate in a workplace PA program (Walk@WorkSpain). Ongoing research should focus on more heterogonous samples of office employees. In addition, sitting time and PA were measured by selfreport. Estimates of workplace sitting are generally higher when measured using objective devices than when measured by self-report [40]. Furthermore, selfreport estimates of work performance/productivity and mental well-being have the potential to contain error. However, in the current study these domains were measured by using two scales with high validity and reliability. Objective measures of sitting time are needed to generate deeper insights into the relationship between total and specific sitting domains with employee's wellbeing and productivity.

\section{Conclusion}

Our findings present a strong rationale, based on consistent associations, for combining sitting time reduction strategies with efforts to increase PA in interventions aimed at improving office employees' well-being and productivity. The study identified distinctive associations depending on pre-existing PA levels. In highly active employees, less total sitting time and occupational sitting on work days was associated with better mental well-being and work performance. In inactive employees, higher levels of PA were related to better mental health and higher performance estimates. This study also suggests that workplace
PA programs promoting "sitting less" in different domains -including weekends - may beneficially impact work productivity and mental well-being. Future research should investigate the impact of workplace sitting time reduction strategies on work productivity and mental well-being among employees engaged in different levels of pre-existing PA.

\section{Competing interests}

The authors declare that they have no competing interests.

\section{Authors' contributions}

$A P$ and NG contributed to the research design. AP, IM, MG, AG and JF led data collection at the universities, with support from JB. LM performed the statistical analyses. AP drafted the manuscript. JM and NG edited and revised the manuscript. All authors commented on drafts, and read and approved the final manuscript.

\section{Acknowledgements}

The authors gratefully acknowledge the Spanish Ministry of Science and Innovation (MICCIN) for providing the funding (project reference DEP 2009-1147) as well as the support of the academic and administrative staff from the Spanish universities who made this study possible.

\section{Author details}

${ }^{1}$ Departament de Ciències de l'Activitat Física, Universitat de Vic, Barcelona, Spain. ${ }^{2}$ Universidad de Vigo, Vigo, Spain. ${ }^{3}$ Physical Activity and Sport Sciences Department, FPCEE Blanquerna, Universitat Ramon Llull, Barcelona, Spain. ${ }^{4}$ Departamento de Educación Física y Deportiva, Universidad del País Vasco, Leioa, Spain. ${ }^{5}$ Physical Therapy Department, FCS Blanquerna, Universitat Ramon Llull. Esport3 Association, Barcelona, Spain. ${ }^{6}$ Unitat de Suport a la Recerca Metropolitana Nord, Institut Universitari d'Investigació en Atenció Primària Jordi Gol (IDIAP Jordi Gol), Santa Coloma de Gramenet, Barcelona, Spain. ${ }^{7}$ School of Sport, Leeds Metropolitan University, Leeds, UK. ${ }^{8}$ School of Human Movement Studies, University of Queensland, St Lucia, Australia. ${ }^{9}$ Departament de Ciències de l'Activitat Física, Universitat de Vic, Carrer de la Sagrada Família, 7, 08500 Vic (Barcelona), Catalonia, Spain.

Received: 16 October 2014 Accepted: 20 January 2015

Published online: 31 January 2015

\section{References}

1. Hallal PC, Andersen LB, Bull FC, Guthold R, Haskell W, Ekelund U. Global physical activity levels: surveillance progress. Lancet. 2012;380:247-57.

2. Lee MI, Shiroma EJ, Lobelo F, Puska P, Blair SN, Katzmarzyk PT. Effect of physical inactivity on major non-communicable diseases worldwide: an analysis of burden of disease and life expectancy. Lancet. 2012;380:219-29.

3. Sedentary Behaviour Research Network. Standarized use of the term "sedentary" and "sedentary behaviours". Appl Physiol Nutr Metab. 2012;37:1-3.

4. Chau JY, Grunseit AC, Stamatakis E, Brown WJ, Matthews CE, Bauman AE, et al. Daily sitting time and all-causes mortality: a meta-analysis. PLoS One. 2013;8:e80000

5. Stamatakis E, Chau JY, Pedisic Z, Bauman A, Macniven R, Coombs N, et al. Are sitting occupations associated with increased all-cause, cancer, and cardiovascular disease mortality risk? A pooled analysis of the seven British population cohorts. PLoS One. 2013;8:e73753.

6. Chau JY, Grunseit A, Midthjell K, Holmen J, Holmen TL, Bauman AE, et al. Sedentary behavior and risk of mortality from all-causes and cardiometabolic diseases in adults: evidence from the HUNT3 population cohort. Br J Sports Med 2013, May 10. Epub ahead of print

7. Ford ES, Caspersen CJ. Sedentary behavior and cardiovascular disease: a review of prospective studies. Int J Epidemiol. 2012:41:1338-53.

8. Thorp AA, Owen N, Neuhaus M, Dunstan DW. Sedentary behaviors and subsequent health outcomes in adults. A systematic review of longitudinal studies, 1996-2011. Am J Prev Med. 2011:41:207-15.

9. Holden L, Scuffham PA, Hilton MF, Ware RS, Vecchio N, Whiteford HA Health-related productivity losses increase when the health condition is comorbid with psychological distress: findings from a large cross-sectional sample of working Australians. BMC Public Health. 2011;11:417-22. 
10. Pronk NP, Kottke TE. Physical activity promotion as a strategic corporate priority to improve worker health and business performance. Prev Med. 2009;49:316-21.

11. Brown HE, Gilson ND, Burton NW, Brown WJ. Does physical activity impact on presenteeism and other indicators of workplace well-being? Sports Med. 2011:41:249-62.

12. Cadilhac DA, Cumming TB, Sheppard L, Pearce DC, Carter R, Magnus A. The economic benefits of reducing physical inactivity in an Australian sample. Int J Behavio Nutr Phys Act. 2011;8:99-105.

13. Goetzel RZ, Long SR, Ozminkoski RJ, Hawkins K, Wang S, Lynch W. Health, absence, disability and presenteeism cost estimates of certain physical and mental health conditions affecting US employees. J Occup Environ Med. 2004:46:398-412.

14. Hamer M, Stamatakis E. Prospective study of sedentary behavior, risk of depression, and cognitive impairment. Med Sci Sports Exerc 2013, epub ahead of print.

15. Atkin AJ, Adams E, Bull FC, Biddle SJ. Non-occupational sitting and mental well-being in employed adults. Ann Behav Med. 2012;43:181-8.

16. Brown HE, Ryde GC, Gilson ND, Burton NW, Brown WJ. Objectively measured sedentary behavior and physical activity in office employees: relationships with presenteeism. Occup Environ Med. 2013:55:945-53.

17. Craig CL, Marshall AL, Sjöström M, Bauman AE, Booth ML, Ainsworth BE, et al. International physical activity questionnaire: 12 country reliability and validity. Med Sci Sports Exerc. 2003;35:1381-95.

18. Marshall AL, Miller YD, Burton NW, Brown WJ. Measuring total and domain-specific sitting: a study of reliability and validity. Med Sci Sports Exerc. 2010;42:1094-102.

19. Tennant R, Hiller L, Fishwick R, Platt S, Joseph S, Weich S, et al. The WarwickEdinburgh Mental Well-Being Scale (WEMWBS): development and UK validation. Health Qual Life Out. 2007;5:63.

20. Lerner D, Amick III BC, Rogers WH, Malspeis S, Bungay K, Cynn D. The work limitations questionnaire. Med Care. 2001;39:72-85.

21. Blanca R, Serra-Majem L, Hagströmer M. International physical activity questionnaire: reliability and validity in Spain. Med Sci Sports Exerc. 2006;38:S563.

22. Acquadro C, Conway K, Giroudet C. Linguistic validation manual for health outcome assessments. Lyon: Mapi Institute; 2004.

23. Castellví $P$, Forero CG, Codony M, Vilagut G, Brugulat P, Medina A, et al. The Spanish version of the Warwick-Edinburgh Mental Well-Being Scale (WEMWBS) is valid for use in the general population. Qual Life Res. 2014;23:857-68.

24. Mapi Research Institute. Linguistic validation certificate: work limitations questionnaire. Lyon: Mapi Research Institute; 2006.

25. Puig-Ribera A, McKenna J, Gilson N, Brown WJ. Measuring presenteesim in Catalan employees: linguistic adaptation and validation. Int J Work Health Manag. 2008;1:198-208.

26. Hamer M, Stamatakis E, Mishra GD. Television- and screen-based activity and mental well-being in adults. Am J Prev Med. 2010;38:375-80.

27. Petersen CB, Nielsen AJ, Bauman A, Tolstrup JS. Joint association of physical activity in leisure and total sitting time with metabolic syndrome amongst 15,235 Danish adults: a cross-sectional study. Prev Med. 2014;69:5-7.

28. Chu AH, Moy FM. Joint association of sitting time and physical activity with metabolic risk factors among middle-aged Malays in a developing country: a cross-sectional study. PLoS One. 2013;8:e61723

29. Rosenkranz RR, Duncan MJ, Rosenkranz SK, Kolt GS. Active lifestyles related to excellent self-rated health and quality of life: cross sectional findings from 194,545 participants in The 45 and Up Study. BMC Public Health. 2013;13:1071.

30. Södergren M, McNaughton SA, Salmon J, Ball K, Crawford DA. Associations between fruit and vegetable intake, leisure-time physical activity, sitting time and self-rated health among older adults: cross-sectional data from the WELL study. BMC Public Health. 2012;12:551.

31. van Uffelen JG, van Gellecum YR, Burton NW, Peeters G, Heesch KC, Brown WJ. Sitting-time, physical activity, and depressive symptoms in mid-aged women. Am J Prev Med. 2013;45:276-81.

32. Spring B, Schneider $K$, McFadden H, Vaughn J, Kozak AT, Smith M, et al. Make Better Choices (MBC): study design of a randomized controlled trial testing optimal technology-supported change in multiple diet and physical activity risk behaviors. BMC Public Health. 2010;10:586.
33. Mansoubi M, Pearson N, Biddle SJ, Clemes S. The relationship between sedentary behaviour and physical activity in adults: a systematic review. Prev Med. 2014;69:28-35

34. Clemes SA, O'connell SE, Edwardson CL. Office workers' objectively measured sedentary behavior and physical activity during and outside working hours. J Occup Environ Med. 2014;56:298-303.

35. Thorp AA, Healy GN, Winkler E, Clark BK, Gardiner PA, Owen N, et al. Prolonged sedentary time and physical activity in workplace and non-work contexts: a cross-sectional study of office, customer service and call centre employees. Int J Behav Nutr Phys Act. 2012;9:128.

36. Owen N, Sugiyama T, Eakin EE, Gardiner PA, Tremblay MS, Sallis JF. Adults' sedentary behavior determinants and interventions. Amer J Prev Med. 2011:41:189-96

37. Sears LE, Shi Y, Coberley CR, Pope JE. Overall well-being as a predictor of health care, productivity, and retention outcomes in a large employer. Popul Health Manag. 2013;16(6):397-405.

38. Page KM, Milner AJ, Martin A, Turrell G, Giles-Corti B, LaMontagne AD. Workplace stress: what is the role of positive mental health? J Occup Environ Med. 2014;56(8):814-9.

39. Nutbem D, Bauman A. Evaluation in a nutshell. A practical guide to the evaluation of health promotion programs. Sydney: McGraw-Hill; 2006.

40. Ryan CG, Grant PM, Dall PM, Granat MH. Sitting patterns at work: objective measurement of adherence to current recommendations. Ergonomics. 2011;54:531-8.

\section{Submit your next manuscript to BioMed Central and take full advantage of:}

- Convenient online submission

- Thorough peer review

- No space constraints or color figure charges

- Immediate publication on acceptance

- Inclusion in PubMed, CAS, Scopus and Google Scholar

- Research which is freely available for redistribution 